\title{
Economic Valuation of Landsat Imagery
}
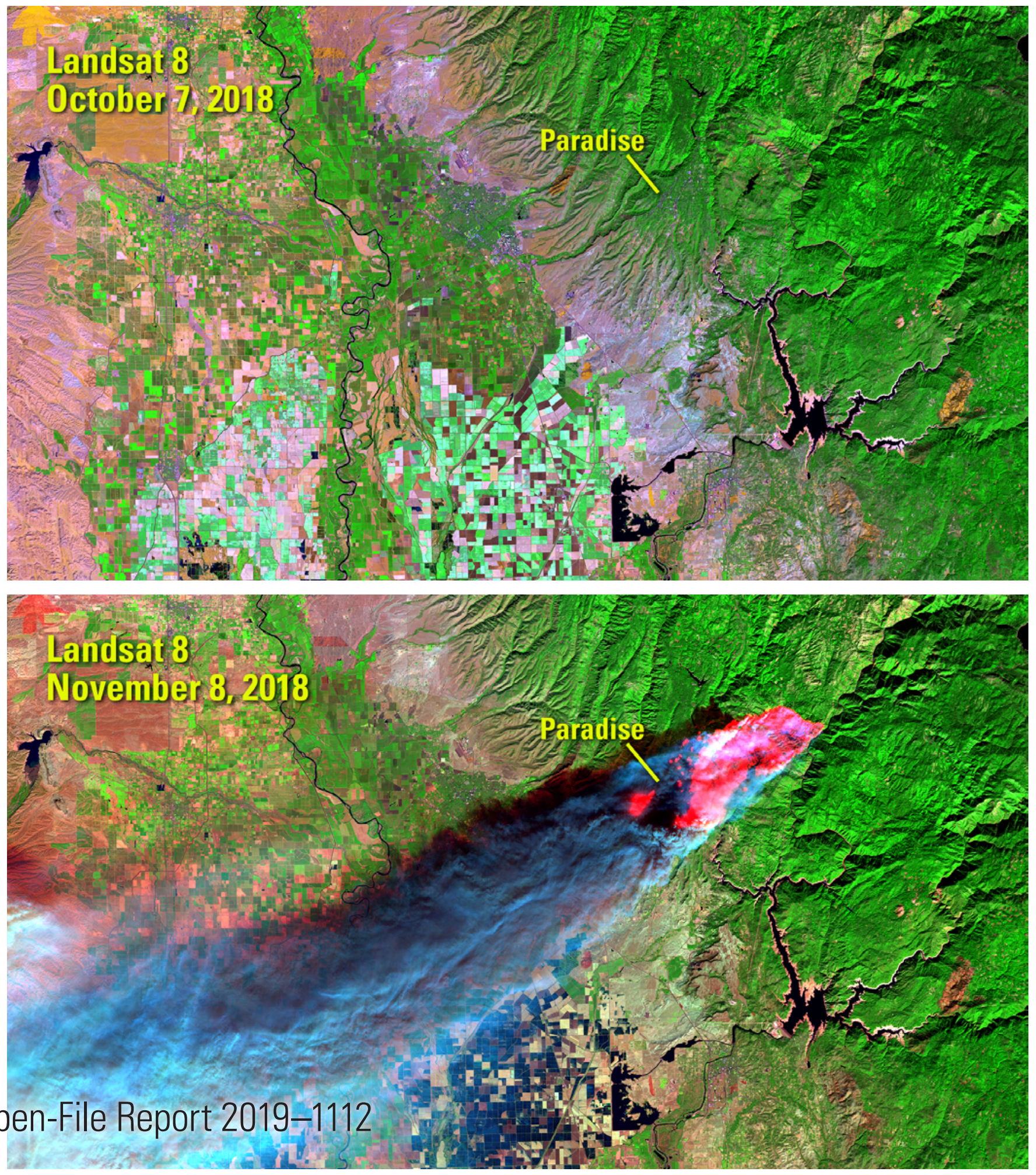

U.S. Department of the Interior

U.S. Geological Survey 
Cover. Landsat images of California before (top) and after (bottom) a 2018 wildfire. (Images courtesy of the U.S. Geological Survey Earth Resources and Observation Science Center, https://eros.usgs.gov/image-of-the-week/california-wildfires). 


\section{Economic Valuation of Landsat Imagery}

By Crista L. Straub, Stephen R. Koontz, and John B. Loomis

Open-File Report 2019-1112

U.S. Department of the Interior

U.S. Geological Survey 


\title{
U.S. Department of the Interior DAVID BERNHARDT, Secretary
}

\author{
U.S. Geological Survey \\ James F. Reilly II, Director
}

U.S. Geological Survey, Reston, Virginia: 2019

For more information on the USGS - the Federal source for science about the Earth, its natural and living resources, natural hazards, and the environment-visit https://www.usgs.gov or call 1-888-ASK-USGS.

For an overview of USGS information products, including maps, imagery, and publications, visit https://store.usgs.gov.

Any use of trade, firm, or product names is for descriptive purposes only and does not imply endorsement by the U.S. Government.

Although this information product, for the most part, is in the public domain, it also may contain copyrighted materials as noted in the text. Permission to reproduce copyrighted items must be secured from the copyright owner.

Suggested citation:

Straub, C.L., Koontz, S.R., and Loomis, J.B., 2019, Economic valuation of Landsat imagery: U.S. Geological Survey Open-File Report 2019-1112, 13 p., https://doi.org/10.3133/ofr20191112.

ISSN 2331-1258 (online) 


\section{Contents}

Abstract

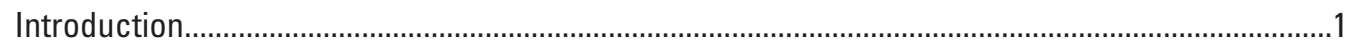

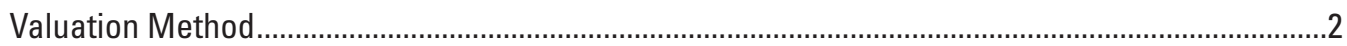

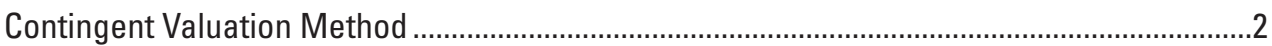

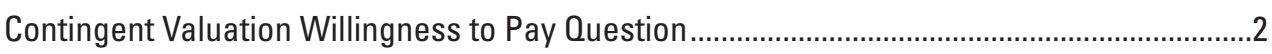

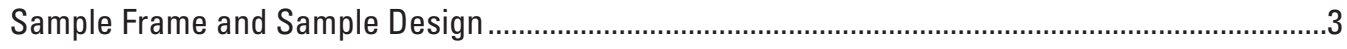

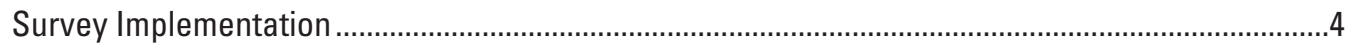

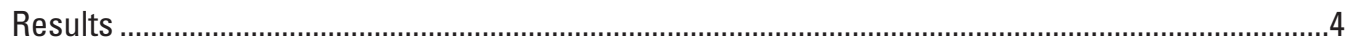

Reasons Why the 2018 Estimated Values per Scene May be Lower Bound Estimates of the User Benefits per Scene ......................................................................................

Resulting High Levels of "Protest" Responses Compared to 2012........................................10

Annual Value of Landsat........................................................................................................

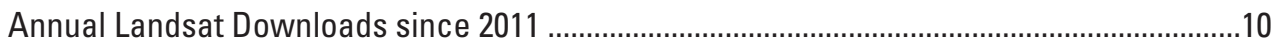

Annual Total Valuation of Landsat Imagery to Direct Users......................................................11

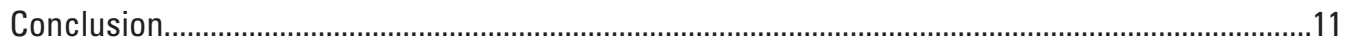

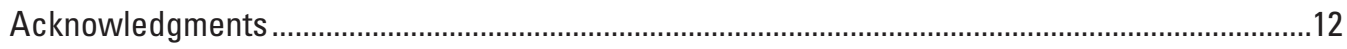

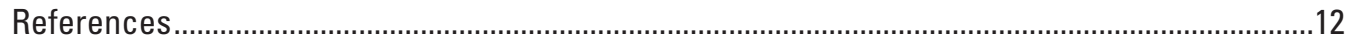

\section{Figures}

1. Demand curves from the combination of two modeling (single and double bound) and two willingness to pay (WTP) questioning approaches (the question asked on the 2012 survey [WTP Original] and the question asked on the 2018 survey [WTP Trust Fund]) as reported by U.S. domestic users

2. Demand curves for the original willingness to pay (WTP) (Original WTP) question using the double bounded dichotomous choice contingent valuation method model.....6

3. Use of Landsat imagery over time based on direct scenes downloaded from the Earth Resources Observation and Science Center ........................................................10

\section{Tables}

1. Median and mean values of economic benefits from a Landsat scene reported by U.S. domestic and international users in response to willingness to pay surveys ...........5

2. Mean values of economic benefits of a Landsat scene to U.S. domestic users by sector

3. Median values of economic benefits of a Landsat scene to U.S. domestic users by sector.

4. Annual aggregate economic benefits to Landsat users registered with the U.S. Geological Survey from Landsat imagery distributed by the Earth Resources Observation and Science Center in 2011 and 2017 


\section{Abbreviations}

CVM contingent valuation method

EROS Earth Resources Observation and Science [Center]

WTP willingness to pay 


\title{
Economic Valuation of Landsat Imagery
}

\author{
By Crista L. Straub, ' Stephen R. Koontz, ${ }^{2}$ and John B. Loomis ${ }^{2}$
}

\begin{abstract}
Landsat satellites have been operating since 1972, providing a continuous global record of the Earth's land surface. The imagery is currently available at no cost through the U.S. Geological Survey (USGS). A previous USGS study estimated that Landsat imagery provided users an annual benefit of $\$ 2.19$ billion in 2011, with U.S. users accounting for $\$ 1.79$ billion of those benefits. That study, published in 2013, surveyed users in 2012 about Landsat imagery they retrieved in 2011. But since then, many changes have altered the demand for and supply of remotely sensed imagery and have made the analysis complex. This report updates these estimates, surveying users in 2018 about Landsat images they retrieved in 2017. The report discusses changes in the value per scene in 2017 when compared to 2011 and analyzes the potential consequences of charging fees. Landsat imagery has been available at no cost to the public since 2008, resulting in the distribution of millions of scenes each subsequent year. In addition, tens of thousands of Landsat users have registered with the USGS to access the data. Considering the number of Landsat data users worldwide and the broad range of Landsat data applications, it is difficult to quantify the cascading benefits to society provided by Landsat imagery. The value of Landsat imagery to these users was demonstrated by the substantial aggregated annual economic benefit from the imagery. Landsat imagery provided domestic and international users an estimated \$3.45 billion in benefits in 2017 compared to \$2.19 billion in 2011, with U.S. users accounting for \$2.06 billion of those benefits. Much of the societal value of Landsat stems from the free and open data policy that allows users to access as much imagery as is necessary for their analysis at no cost. Charging even small fees would result in a loss of users and, most likely, a steep decline in the amount of imagery downloaded. It is reasonable that more than 50 percent of users will decline to pay. The consequences of charging for Landsat imagery would be felt by downstream users as well, through increased prices for value-added products as well as more intangible effects, such as reduced monitoring of environmental hazards.
\end{abstract}

\section{Introduction}

The purpose of this report is to provide an update on the economic benefits of Landsat imagery. Since 1972, the joint National Aeronautics and Space Administration/U.S. Geological Survey Landsat series of Earth observation satellites have continuously acquired space-based images of the Earth's land surface, providing uninterrupted data to help land managers and policymakers make informed decisions about our natural resources and the environment. Every year, the U.S. Geological Survey distributes millions of these remotely sensed Landsat images to thousands of users at no cost. These images are used for commercial applications and in derived products, such as Google Earth, which themselves have millions of users. There are numerous sources that provide access to Landsat data including Amazon Web Services, the Environmental Systems Research Institute, Google Earth Engine, and other sources. Landsat data is used in value-added products (the National Land Cover Dataset, LANDFIRE, the Global Land Survey, and Land Surface Reflectance) as well as in water-monitoring efforts (Serbina and Miller, 2014) and the monitoring of agricultural resources (Leslie and others, 2017). Landsat is one of the most critical civil U.S. Earth observation systems (Office of Science and Technology Policy, 2014) and improvements in Landsat science expand the use of the technology by operational and scientific groups for use in forestry, urbanization, homeland security, disaster mitigation, and other applications (Tourangeau and Plewes, 2013; National Academies of Science, 2018).

Though the widespread use of Landsat imagery indicates it provides benefits to users, the nonmarket status of the data can make it difficult to determine the current value of the data to users and society at large. Previous research using the contingent valuation method (CVM) demonstrated that Landsat imagery provides billions of dollars of benefits to users (Miller and others, 2013). These data were collected in 2012 for a survey (referred to in this report as the "2012 survey"), and since that time there

\footnotetext{
${ }^{1}$ U.S. Geological Survey.
}

${ }^{2}$ Colorado State University. 
have been many changes in both the demand for and supply of remotely sensed imagery. Two particular changes have important ramifications for our valuation effort: (1) a new supply of free imagery is now available from the European Space Agency's Sentinel-2A and -2B satellites and (2) discussions regarding charging for Landsat imagery are taking place within the remote sensing community (Popkin, 2018). The economic ramifications of these two developments will be discussed in the "Results" section. This report is the first of a set of three companion reports. The two additional reports cover (1) stated choice models and (2) Landsat user characteristics and use. The three reports were developed in response to the "Users, Uses, \& Value of Landsat Satellite Imagery: 2018 User Survey" (referred to in this report as the "2018 survey").

\section{Valuation Method}

\section{Contingent Valuation Method}

Economists measure the economic value of any product, whether a market or nonmarket good, based on the maximum amount a person would pay rather than go without the product (Stokey and Zechauser, 1978; Office of Management and Budget, 1992; Brent, 1996). Two terms often used interchangeably for this concept of benefits are "willingness to pay" (WTP) and "consumer surplus." The CVM is one way to measure value when there is no market for the good or product. Nonmarket valuation methods are widely used by a variety of Federal government agencies (for example, U.S. Environmental Protection Agency, National Park Service, Bureau of Reclamation) for valuing a variety of publicly provided goods (for example, recreation, air quality). The Office of Management and Budget (1992) also recommends using nonmarket valuation to estimate benefits, stating, "When it can be determined, consumer surplus provides the best measure of the total benefit to society from a government program or project" (p. 4).

Landsat imagery has been available at no cost since 2008. Therefore, the 2012 economic valuation of Landsat imagery (2012 survey) and corresponding analysis used methods designed to value nonmarket goods and services that are often not priced, for example, air quality or public lands recreation (Miller and others, 2013). For the 2018 survey, the 2012 survey was replicated and the same nonmarket valuation technique, CVM, was used. Landsat imagery has now been available at no cost for a longer period of time compared to when the 2012 survey data were collected. Because many of the people using Landsat at the time of the 2018 survey may have never paid for Landsat imagery, the case for using a nonmarket valuation method is even stronger than when it was implemented during the 2012 survey.

\section{Contingent Valuation Willingness to Pay Question}

The 2012 survey (Miller and others, 2013; Loomis and others, 2015) successfully used a closed-ended or dichotomous choice WTP approach. Therefore, we kept the 2012 survey question as the primary valuation question. This approach allowed a longitudinal analysis of the 2012 and 2018 survey results; any differences in value between the two surveys would be attributable to changes in the demand and supply of satellite imagery as well as any information respondents may have on potential changes in Landsat pricing policy. The question asked on the 2012 survey, which is referred to as "WTP Original" in this report, is paraphrased below:

In the event that Landsat imagery was no longer available, you may have to obtain imagery elsewhere. Assume that you are restricted to your current project or organization budget level and that the money to pay any cost for replacement imagery and additional software or training would have to come out of your existing budget. If you had to pay for imagery that was equivalent to currently available Landsat imagery, would you pay $\$ X$ for one scene covering the area equivalent to a Landsat scene?

The "\$X"s were the "bid" amounts that respondents were asked to pay. Following standard practice for the CVM, respondents were asked if they would pay one of 13 randomly assigned dollar amounts. For the 2018 survey, the dollar amounts were based on the results of the 2012 survey and ranged from $\$ 55$ to $\$ 4,400$ per scene.

Responses to this type of closed-ended, or dichotomous choice, question are usually analyzed, following standard practice, using a logistic regression model (Champ and others, 2017). The dependent variable is the respondent's "Yes" $(=1)$ or "No" $(=0)$ answer as a function of the dollar amount they were asked to pay. This statistical approach is a single bounded dichotomous choice model that uses only the answers to the first WTP question and is indicated with "Single or Single Bound" in the tables and graphs that follow. Other explanatory variables were included to examine for differences in value among different types of users.

Using a follow-up CVM WTP question allows for increased precision of the estimates of economic benefits. If the respondent answered "Yes" to the first question, then a second question asked if they would pay a higher amount. If the respondent answered "No" to the first question, then a second question asked if they would pay a lower amount. The response 
to these two questions leads to a series of "Yes"/"Yes," "Yes"/"No", "No"/"Yes," and "No"/"No" answers. The primary gain in precision arises from the "Yes"/"No" and the "No"/"Yes" responses because the respondent's WTP is now bracketed between the first dollar amount they are asked and the second dollar amount they are asked. Taken together, all four of these responses provide the data necessary to estimate a "double bounded" statistical model (Hanemann and others, 1991). The benefit estimates calculated from the double bounded dichotomous choice model is indicated with the label "Double or Double Bound" in the tables and graphs that follow.

The coefficients from the logistic regression are used to calculate the median dollar amount that 50 percent of users would pay per scene. The mean value that users would pay per scene can be calculated by integration of the logistic curve. The mean value can be multiplied times the number of downloaded scenes to calculate the annual aggregate value of all downloaded scenes across all types of user groups (for example, domestic versus international).

To address the issue of strategic bias and protest responses, an alternative form of the WTP question was administered to a different sample group of registered Landsat users. Strategic bias and protest responses were apparent in the first wave of the 2018 survey responses. A protest response is when the survey respondent does not state the true WTP value for the good in question for a particular reason. Survey participants may exhibit strategic behavior by understating the amount they would pay, or simply refusing to pay, so as to send a signal that they are opposed to charging, especially when the good has been free for a decade (Campos and others, 2007). In these cases, respondents are worried that indicating an amount they would pay would result in charging for this previously free good. This phenomenon has been found in other CVM surveys (Campos and others, 2007). Even when the good has a current price, such as a hunting license, respondents tend to provide valuation responses to CVM WTP questions that are statistically lower than what actual demand estimates based on actual hunting license price increases indicate they would pay (Loomis and others, 2000). The users make this understatement of their WTP so as to send a message in the survey hoping to avoid or at least minimize future increases in fees. These particular responses in the 2018 survey were likely due to respondents' awareness about the Landsat community discussions and (or) articles surrounding a potential change to the Landsat policy of free and open access to Landsat images. Therefore, we developed a WTP survey question that asked about using payments made to a trust fund to pay for the next version of the Landsat satellite. The question asked, which is referred to as "WTP Trust Fund" in this report, is paraphrased below.

The current and proposed Federal budgets provide sufficient funding to maintain the current Landsat program, but not for building and launching the replacement to Landsat 8, namely Landsat 9. Landsat 9 is equivalent to Landsat 8 with a likely launch in 2021. The cost of building and launching Landsat 9 has increased in recent years. In order to provide funding for building and launching Landsat 9, a trust fund would be established. The per image download fee would provide money that would be used exclusively for the purpose of building and launching Landsat 9. If Landsat 9 is not built, there may be no Landsat satellite images after Landsat 8 becomes inoperable, sometime during the 2023 time period. Assume that you are restricted to your current project or organization budget level and that the money to pay any cost for replacement imagery and additional software or training would have to come out of your existing budget. Would you pay $\$ \mathbf{X}$ per image into this trust fund for building and launching Landsat 9 , and replacing Landsat 8 ?

The intent of this question was to ascertain if providing a rationale for why a charge might occur and how the money collected would be dedicated to future Landsat satellites would reduce protest responses. The same range of dollar amounts used for the "WTP Original" question was used for the "WTP Trust Fund" question to ensure any differences in estimated WTP were because of the different wording of the two questions.

\section{Sample Frame and Sample Design}

The population used for this study comprised all individuals that accessed Landsat images through Earth Resources Observation and Science (EROS) Center during the 2017 calendar year, the year prior to the 2018 survey. The population did not include downstream and secondary users that did not obtain imagery from EROS — only direct or initial EROS registered users of Landsat images. We say direct or initial users, as we are aware that there may be millions of subsequent users of the images produced by the initial users (for example, users of Google ${ }^{\mathrm{TM}}$ maps, GPS programs, cloud vendors). Thus, our estimates of the benefits of Landsat images are conservative because only the initial/direct EROS registered users were sampled.

A U.S. Federal user survey was conducted first. A list of 914 email addresses was provided by EROS. After duplicate and nonworking email addresses were removed, 895 addresses remained. We then conducted a non-Federal U.S. user survey in combination with an international user survey. A list of 125,565 email addresses was provided by EROS. Of those, 80,055 were international users with a specific, self-identified country outside of the United States and U.S. territories. There were 13,962 users that self-identified as being in the United States or a U.S. territory. We conducted a census of the U.S. users. We 
used a random sample of the international users to equal the number of U.S. users $(13,962)$. After duplicate and nonworking email addresses were removed, 27,313 addresses remained. All respondents received the questions in the same order. A variety of questions were asked of the respondents, prior to the WTP questions, including questions related to the specific use and qualitative value of satellite imagery. We also incorporated stated choice modeling to gain new insight into user requirements related to the needs of the user community and future satellite features. The WTP questions came near the end of the survey because by that point in the survey, respondents had time to think about the "good" (for example, Landsat images) in a nonmonetary way prior to being asked to think about the value of the good to themselves in monetary terms. The respondents who started using Landsat after 2008 and had never paid for imagery might have found it difficult to answer the WTP questions if they were located at the beginning of the survey.

The WTP Trust Fund question was used for the non-Federal U.S. user survey/international user survey. The question was sent to 25 percent of the respondents who were randomly selected.

\section{Survey Implementation}

The U.S. Federal user survey was launched February 13, 2018. The non-Federal U.S. user survey/international user survey was launched August 29, 2018. The implementation for both survey launches used the Dillman (2017) repeat contact method ( $\sim 10$ repeat contacts) to attain as high a survey response rate as feasible. For the U.S. Federal user survey, a total of 251 individuals responded to the survey, for a response rate of 28 percent. This number includes both completed surveys $(\mathrm{n}=205)$ and partially completed surveys $(\mathrm{n}=46)$. For the non-Federal U.S. user survey/international user survey, a total of 4,454 individuals responded to the survey, for a response rate of 16 percent. This number includes both completed surveys $(n=3,310)$ and partially completed surveys $(n=1,144)$. This response rate is comparable to recent email/web survey responses (Petchenik and Watermolen, 2011; Tourangeau and Plewes, 2013; Dillman and others, 2014; Dillman, 2017).

\section{Results}

We first present results on the value per scene by different types of user groups and discuss why these values are different than the 2012 survey results. Then, we present the total annual value of Landsat imagery based on the total number of scenes downloaded by each group. Even if the value per scene decreased, the large increase in the number of scenes downloaded has resulted in an increase in the total annual value of the Landsat program.

Three tables of imagery valuations provide the mean and median WTP. Similar to the 2012 survey valuation approach, we analyzed and estimated values separately for domestic versus international users. This is because U.S. domestic user valuations are significantly different from international user valuations.

In prior Landsat valuation research from the 2012 survey, imagery valuations were presented for established versus new/returning users. The 2012 survey valuations were also presented for a number of different categories of users: nonprofit organizations, Federal governments, private businesses, State and local governments, and academic users. For the 2018 survey, we have reduced the number of categories. Part of this reduction is because Landsat has offered free imagery for a long enough period of time that there is no discrete difference between established and new/returning users. However, a variable that measures the number of years each individual used Landsat imagery was included. The longer an individual used Landsat imagery, the higher they value the imagery. There is no difference in the valuation between new or established users. Further, the 2018 survey had smaller respondent groups of some categories of users, for example, nonprofit organizations. In examining the valuation by different categories of users we find that Federal government employees and private business users have different mean values than all other categories. Thus, all other categories are combined and reflected in the overall intercept term of the logistic regression. The largest segment of this other category is academic users. Academic users are not statistically different from, for example, nonprofit organizations, State and local governments, or indigenous Tribes.

A difference between this study (2018 survey) and prior work (2012 survey) is that the 2018 survey used the EROS metadata to determine the number of unique scenes downloaded by the user completing the survey. The coefficient of the number of scenes downloaded variable is negative and significant. This indicates that, if the number of years of Landsat use and other variables such as user type are held constant, the probability the respondent would pay a given dollar amount per scene goes down as the number of scenes a user downloads increases. This may be expected because the wording in the CVM WTP questions informed respondents to answer assuming they are constrained to their current budgets. Such a request is a recommended protocol (Arrow and others, 1993) and is commonly done in CVM WTP studies to encourage realistic answers to WTP questions.

In table 1, the median is the bid amount that produces a probability of 50 percent; that is, it is the value that the typical respondent has an equal probability of agreeing to pay or not agreeing to pay. This is shown in figure 1 and even more distinctly 
in figure 2 that shows that if 50 percent is chosen on the $\mathrm{x}$-axis, the demand function reveals $\$ 56$. Charging $\$ 56$ per scene for imagery would result in one-half of the current users agreeing to pay and one-half not agreeing to pay. Thus, charging $\$ 56$ per scene would eliminate one-half of Landsat users.

Table 1. Median and mean values of economic benefits from a Landsat scene reported by U.S. domestic and international users in response to willingness to pay (WTP) surveys. The table provides the median and mean values for respondent subsamples that answered (1) the original format of the WTP question that used the same wording as the WTP question on the 2012 Landsat survey (WTP Original) and (or) (2) the trust fund WTP question (WTP Trust Fund). WTP results are presented using the double bound dichotomous choice contingent valuation method model (best performing and more conservative statistical model).

[U.S. United States; \%, percent, CI, confidence interval; LB, lower bound]

\begin{tabular}{|c|c|c|c|c|c|c|c|c|}
\hline \multirow{2}{*}{$\begin{array}{l}\text { Value per } \\
\text { Landsat scene }\end{array}$} & \multicolumn{4}{|c|}{ U.S. users } & \multicolumn{4}{|c|}{ International users } \\
\hline & $\begin{array}{c}\text { WTP } \\
\text { Original }\end{array}$ & $\begin{array}{c}90 \% \mathrm{Cl} \text { and } \\
\text { LB }\end{array}$ & $\begin{array}{l}\text { WTP Trust } \\
\text { Fund }\end{array}$ & $\begin{array}{c}90 \% \mathrm{Cl} \text { and } \\
\text { LB }\end{array}$ & $\begin{array}{c}\text { WTP } \\
\text { Original }\end{array}$ & $\begin{array}{c}90 \% \mathrm{Cl} \text { and } \\
\text { LB }\end{array}$ & $\begin{array}{l}\text { WTP Trust } \\
\text { Fund }\end{array}$ & $\begin{array}{c}90 \% \mathrm{Cl} \text { and } \\
\text { LB }\end{array}$ \\
\hline Median & $\$ 56$ & $\$ 44-\$ 71^{1}$ & $\$ 53$ & $\$ 37-\$ 73^{1}$ & $\$ 41$ & $\$ 30-\$ 59^{1}$ & $\$ 45$ & $\$ 23-\$ 72^{1}$ \\
\hline Mean & $\$ 183$ & $\$ 74^{2}$ & $\$ 180$ & $\$ 52^{2}$ & $\$ 203$ & $\$ 81^{2}$ & $\$ 227$ & $\$ 55^{2}$ \\
\hline
\end{tabular}

${ }^{1}$ Confidence interval— double bound model.

${ }^{2}$ Lower bound - double bound model.

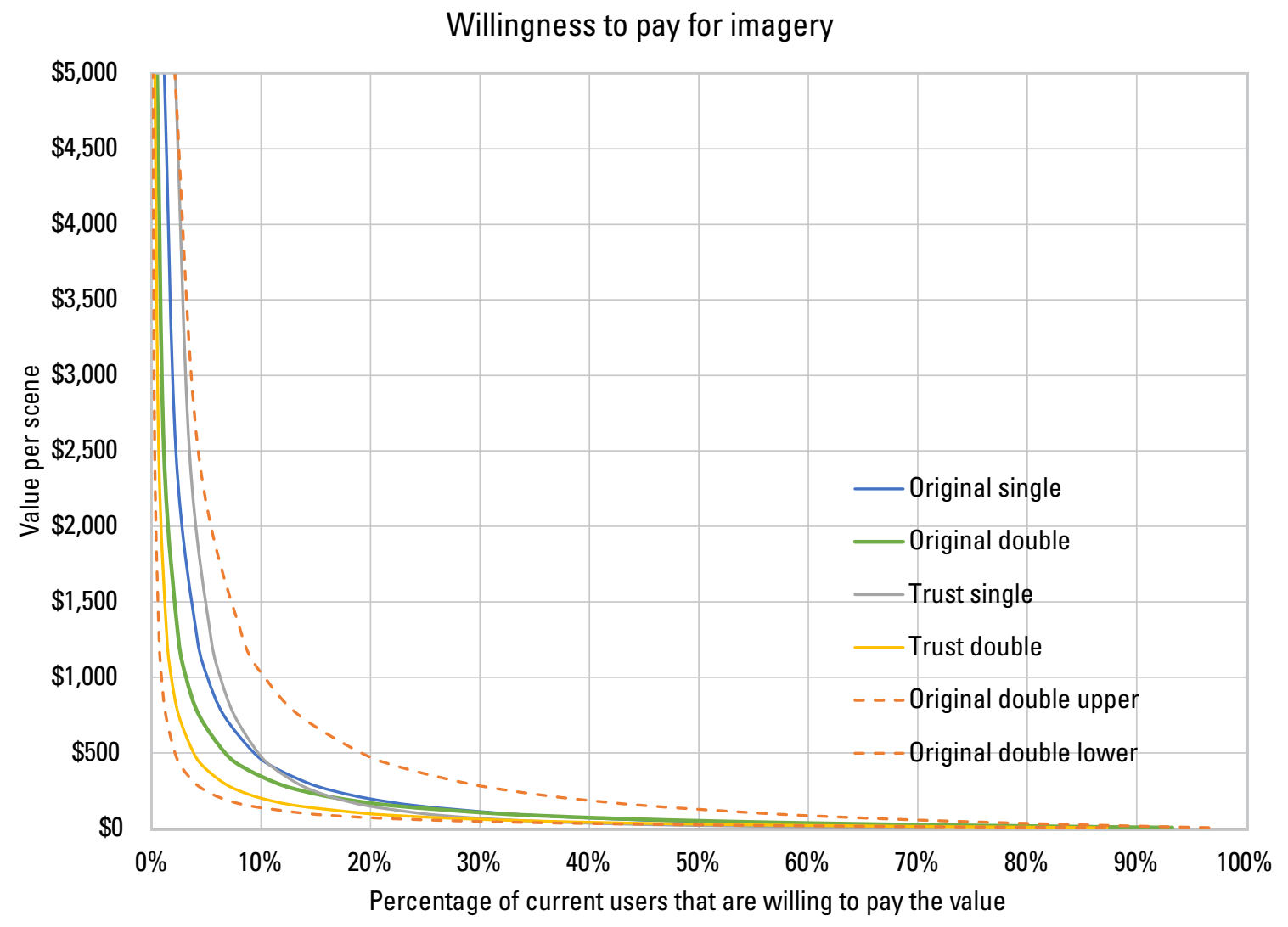

Figure 1. Demand curves from the combination of two modeling (single and double bound) and two willingness to pay (WTP) questioning approaches (the question asked on the 2012 survey [WTP Original] and the question asked on the 2018 survey [WTP Trust Fund]) as reported by U.S. domestic users. $(\%$, percentage $)$ 


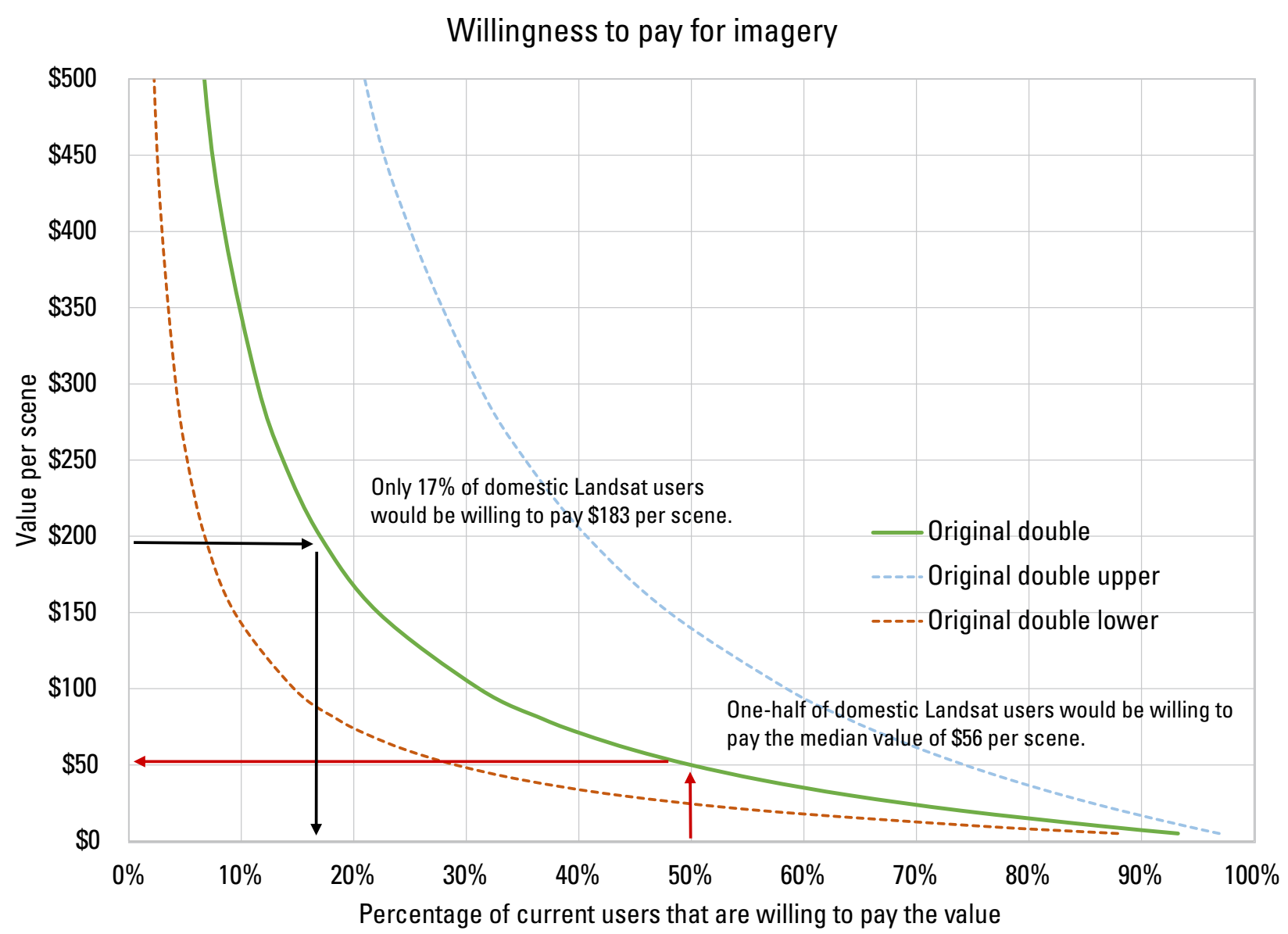

Figure 2. Demand curves for the original willingness to pay (WTP) (Original WTP) question using the double bounded dichotomous choice contingent valuation method model. The figure shows that the demand curve zooms in the lower section where the majority of U.S. domestic Landsat users' valuations are observed in the data. $(\%$, percentage)

Table 1 provides the values from the double bound model, which is the best performing statistical model and the more conservative estimate of WTP. However, the two statistical modeling methods (single and double bounded) for U.S. users reveal that the medians are between $\$ 46$ and $\$ 56$ per scene. Although formal statistical testing was not conducted, it is unlikely these two estimates of the median are statistically different. Specifically, the median for each approach is within the confidence interval of the other approach. The WTP Original question format was used for consistency with the earlier 2012 survey and because it had a larger sample size.

International users have median valuations between $\$ 7$ and $\$ 41$ per scene (single and double bounded, WTP Original). The double bounded model had modestly better statistical performance. The international user portion of the valuation effort shows more uncertainty and variability in response to the WTP Original compared to domestic users. However, international users had more stable responses between the first and second questions (that is, the double and single bounded WTP questions) when asked about their WTP in the trust fund context.

Each type of statistical model has a straightforward way to determine the median valuation per scene, but not the mean, or expected value, valuation per scene. This is because the demand function approaches, but does not touch, the y-axis. Therefore, the mean value is unbounded. In order to calculate the mean, numerical integration of the demand function must be used, and a finite vertical intercept selected based on the response data. Specifically, a bid amount must be selected above which no user will agree to pay. Based on our survey responses, the bid amount of $\$ 3,300$ was selected as the vertical intercept as it was the highest bid amount with "Yes" answers to the WTP questions.

In table 1, we see that mean value per scene for domestic users is $\$ 183$ when the respondents were asked a question using the same wording of the WTP question that was used in 2012 survey (WTP Original). The value of $\$ 183$ is from the 
largest sample size group with the best statistical performance. For international users, the mean valuation is higher, $\$ 203$, using the same wording of the WTP question as was used in the 2012 survey (WTP Original). The value of \$227 is from the international sample group in response to the WTP Trust Fund question and the best performing statistical model (double bounded). Thus, it is safe to say that the mean valuation per scene for Landsat imagery is approximately $\$ 200$ for domestic users and somewhat more than $\$ 200$ for international users. The mean values are all large compared to the medians because the mean WTP relies on the entire distribution of users along the entire WTP curve. The vast majority of Landsat imagery users have a relatively low value for Landsat imagery compared to the alternative sources of imagery. However, there is a small portion of the user base that has a very high value of Landsat imagery. This creates the high mean value but the low median value for the typical user.

Tables 2 and 3 communicate variation in mean and median valuations, respectively, when the number of scenes downloaded is varied and when the years that the respondent has used imagery is varied. Users that download a small number of scenes and have been using Landsat imagery for many years place the highest value on the imagery. This is a small but important group. Survey respondents that download the median number of scenes or less and that have been accessing imagery for the median number of years or more are 23.3 percent of the domestic users. Survey respondents that download the 25th quartile number of scenes or less and that have been accessing imagery for the 75th quartile number of years or more are 5.5 percent of the domestic users. The more scenes a user downloads, the less they are willing to pay per scene, but the longer the user has been accessing imagery, the more they are willing to pay. These users, for whom Landsat imagery is most valuable, could be referred to as "dedicated." Private business users and Federal government users also place high value on the imagery relative to the group of academic users, State and local governments, and nonprofits. Government users may have fixed or shrinking budgets. Federal budgets and projects tend to be larger than State or local budgets and perhaps contribute to the difference in Federal responses. Similarly, private users may be able to pass on costs to customers or clients. For high value users (Low scenes/high years), the mean value is $\$ 332$ per scene and the median value per scene is $\$ 115$ (Across all groups). However, for low value users (High scenes/low years), the mean value is $\$ 89$ and the median value per scene is $\$ 23$ (Across all groups).

Table 2. Mean values of economic benefits of a Landsat scene to U.S. domestic users by sector. Results were analyzed based on the double bounded dichotomous choice contingent valuation method model using the original format of the willingness to pay (WTP) question (WTP Original).

\begin{tabular}{lcccc}
\hline & Academic and other & Private business & Federal government & Across all groups \\
\hline High scenes/low years & $\$ 69$ & $\$ 112$ & $\$ 121$ & $\$ 89$ \\
Low scenes/low years & $\$ 126$ & $\$ 200$ & $\$ 215$ & $\$ 159$ \\
High scenes/high years & $\$ 152$ & $\$ 240$ & $\$ 258$ & $\$ 191$ \\
Low scenes/high years & $\$ 267$ & $\$ 413$ & $\$ 442$ & $\$ 332$ \\
\hline
\end{tabular}

Table 3. Median values of economic benefits of a Landsat scene to U.S. domestic users by sector. Results were analyzed based on the double bounded dichotomous choice contingent valuation method model using the original format of the willingness to pay (WTP) question (WTP Original).

\begin{tabular}{lcccc}
\hline & Academic and other & Private business & Federal government & Across all groups \\
\hline High scenes/low years & $\$ 18$ & $\$ 28$ & $\$ 34$ & $\$ 23$ \\
Low scenes/low years & $\$ 36$ & $\$ 56$ & $\$ 68$ & $\$ 47$ \\
High scenes/high years & $\$ 45$ & $\$ 70$ & $\$ 85$ & $\$ 58$ \\
Low scenes/high years & $\$ 88$ & $\$ 138$ & $\$ 168$ & $\$ 115$ \\
\hline
\end{tabular}

The demand curves in figure 1 describe the probability of a typical respondent agreeing to pay a specific price for a scene of imagery. The four demand functions for imagery are produced using the two questioning formats (WTP Original approach or the WTP Trust Fund context) and two statistical approaches (a single bound dichotomous choice model that used only the answers to the first WTP question and a double bound choice model that used responses to both the first question and the follow-up 
second question). The demand function for imagery from the single bounded model is indicated as "Single" and the similar function from the double bounded model is indicated as "Double."

The general pattern for all four curves is that at low values a typical respondent has a high probability of agreeing to pay the value. As the amount the respondent is asked to pay increases, the WTP is rapidly reduced. However, it is also seen that, as the values are increased further, there is a small segment of typical users who will continue to agree to pay the value. Thus, there is a small proportion of users who have a very high value specifically for Landsat imagery. Most likely these persons are longtime and low-volume users. Conversely, there is a substantial proportion of users who have a low value for the Landsat imagery compared to the next best substitute (Sentinel-2) or imagery from other sources. These persons are most likely recent adopters that use a substantial number of scenes.

There are two reasons the four WTP curves are slightly different: (1) the wording of the WTP question and (2) whether only the first WTP question response or both responses were used in the statistical model. The single bounded model using the trust fund question (WTP Trust Fund) has a slightly higher percentage of users willing to pay the higher values shown on the $y$-axis than the original questioning methods (WTP Original). However, the double bound results using the trust fund question show the fewest number of users willing to pay a given dollar amount. It is also seen that both double bound demand functions are to the left of the single bound functions for the same questioning method. This is a common result in double bound versus single bound research. Some respondents see that their first answer seems to influence the dollar amount asked in the second question, and as a result have a lower probability of saying "Yes" to the second bid amount compared to when that same bid is asked in the first WTP question. This tends to result in a lower overall average and a more conservative estimate of WTP (Hanemann and others, 1991).

The pair of dashed lines in figure 1 are the confidence intervals - upper confidence interval and lower confidence intervalaround the "Original WTP Question Double Bounded" logistic demand function. All four demand functions fit within all the confidence intervals of the other three approaches. The specific type of CVM (for example, single versus double bounded) is slightly different, and the specific question wording (for example, WTP Original versus WTP Trust Fund) is different, but the overall results are very similar. Different questioning approaches and different variations of the underlying statistical models lead to very similar results and very similar conclusions. Thus, the overall results are robust and can be treated with confidence.

Figure 2 zooms in and expands the lower section of the demand curve where the vast majority of Landsat users' valuations are observed in our data. In this graph, we focus just on the original WTP question (WTP Original) format that was used in 2012 survey valuation. The curves are estimated using the double bounded dichotomous choice logistic regression equation. Although we use figure 2 to make inferences about pricing, the reader is strongly urged to keep in mind that the original WTP question asked, like most WTP questions, is used to estimate the value of a nonmarket good, in this case Landsat imagery. The focus of CVM is not necessarily to establish a price to be a charged in a market research context. As described in the following paragraphs and in the original Landsat valuation report (Miller and others, 2013, p. 38-39), charging a price would result in a substantial "deadweight loss" in economic efficiency to society.

Nonetheless, using figure 2, the reader can see that, if domestic users were charged the approximate mean valuation of $\$ 183$ per scene, the number of domestic Landsat users would be estimated to drop by 83 percent, leaving just 17 percent of the current number of users. The confidence interval on this 17 percent is between 6.5 and 38 percent of users remaining at a charge of $\$ 183$ a scene. The remaining users would likely be just the long-time users that also download relatively few scenes (see table 2). Exiting users would likely be the new, innovative, high-volume users.

Charging a price per scene near the median of $\$ 56$ per scene is estimated to result in a loss of one-half of the current Landsat users and a decrease in the number of scenes that are downloaded. The confidence interval suggests that at $\$ 56$ per scene as few as 25 percent of users would remain, at most 70 percent would remain. The remaining users would again likely be long-time users who download relatively few scenes (see table 3 ).

It is rather certain that more than one-half of the current users would not use Landsat imagery if they were charged an amount close to the mean valuation. It is also likely that one-half of the users would stop using Landsat imagery if charged the median value. Tables 2 and 3 indicate that charging for Landsat imagery would displace the vast majority of users because only long-time and low-volume users would be willing to pay. This potentially could greatly diminish the benefits provided by Landsat imagery in terms of scientific advances made by governments as well as the private sector that produce associated innovative, downstream benefits for end users of navigation systems, on-the-ground monitoring technologies, and so on (Zhu and others, 2019). In addition, the consequences of charging for Landsat imagery would be felt by downstream users through increased prices for value-added products (for example, geographic information systems, data apps using Landsat imagery). Charging for Landsat imagery is also likely to decrease Landsat science and application developments. 


\section{Reasons Why the 2018 Estimated Values per Scene May be Lower Bound Estimates of the User Benefits per Scene}

We offer a few reasons why the 2018 survey value per scene may be a lower bound on actual benefits, despite the fact that the total value of Landsat imagery has increased.

1. The length of time that Landsat imagery has been free.-Landsat has been free since 2008, a longer time span than when the 2012 survey was taken. Landsat users may now view this free access as a norm and have "settled" into a free Landsat. This could bring about numerous issues for survey respondents, such as (1) they are not sure how to incorporate Landsat fees into current budgets and (2) they are uncertain about the mechanism by which they would pay for Landsat images. The respondents may have found it difficult to separate cost from value, meaning that, even if the respondents placed a high value on Landsat imagery, they were uncertain about the WTP language and the potential for the money going to the Landsat program. However, unlike other "free" natural resources, Landsat did have a fee at one time. Respondents' concerns about returning to a payment system for Landsat can influence their answers to the 2018 survey questions, as discussed immediately below.

2. Strategic behavior may understate values. - Respondents are potentially aware of and concerned about the potential policy change of charging for Landsat imagery. Respondents may have read articles about these issues before and during survey release. This can induce strategic behavior on the part of the respondent to understate the amount they would pay or indicate that they would not pay in an effort to send a signal that they are opposed to charging, especially when the good has been free for a decade (Campos and others, 2007). In these cases, respondents are worried that specifying an amount they would pay will result in charging for this previously free good. This phenomenon has been found in other CVM surveys (Campos and others, 2007). Even when the good has a current price, such as a hunting license, respondents tend to provide valuation responses to CVM WTP questions that are statistically lower than what actual demand estimates based on actual hunting license price increases indicate they would pay (Loomis and others, 2000). Survey respondents hoping to avoid or at least minimize future increases in fees understate their WTP so as to send a message through the survey.

3. Introduction of Sentinel-2 as no cost substitute for Landsat.- In 2012, there was no lower cost price substitute for Landsat satellite imagery. The 2012 survey measured the entire value of satellite imagery to the respondent. During the time between the first survey in 2012 and the second survey in 2018, the European Space Agency introduced their free satellite imagery. The 2018 survey WTP question likely became a question about how much more or how much of a premium a user would pay for Landsat imagery compared to Sentinel-2 imagery. For some users, Landsat did offer some advantages. First, Landsat has an archive of satellite imagery that is not available for the Sentinel-2 satellites. Second, although Sentinel-2 satellites have spectral bands similar to Landsat 8's, only Landsat 8 has thermal bands. Third, many of the analysts are familiar with using Landsat and have developed applications and software around Landsat. Thus, to some users (for example, long-time users downloading a few images) these advantages of Landsat compared to Sentinel-2 are important and they would pay a significant premium for Landsat imagery. For these types of users, we obtained a positive premium for Landsat, but still not their total value of imagery. For other users (for example, relatively new users who download lots of images) asked to pay relatively high prices for Landsat, the advantages of Landsat compared to Sentinel-2 were just not worth the added cost. For many other users, Sentinel-2 was a perfect substitute, that is, there wasn't really anything that Landsat offered that Sentinel-2 couldn't do as well. Thus, these users would pay nothing or just a $\$ 1$ per scene premium for Landsat (20.58 percent of responses).

4. The survey did not discuss a policy change. - In the survey, there was no mention of any policy change or cost discussion related to the Sentinel-2 program. Therefore, respondents assumed Sentinel-2 would remain free. Respondents only considered Sentinel-2 as a free option when responding to the survey. As noted in \#3 above, this limited WTP for Landsat imagery for those users for whom Sentinel-2 is a perfect substitute (for example, the WTP was near zero) or a near perfect substitute.

5. Users download more scenes now than in 2012 so the potential cost to users has increased. - The number of scenes downloaded increased from 2.9 million in 2011 to 22 million in 2017. Because the number of scenes downloaded per user has increased, the total amount of money respondents would have to pay has increased as compared to 2012 when they downloaded fewer scenes. This led some respondents to indicate they need "too many (scenes) to pay for" when they considered the number of scenes they needed and their current budget. 


\section{Resulting High Levels of "Protest" Responses Compared to 2012}

The issues described in the previous sections explain why the original WTP question (WTP Original) format led to a large number (20.58 percent) of what are called protest responses. If the respondent answered "No"/"No" to the first and second WTP questions, then a final bid amount of \$1 per scene was asked. An answer of "No" to this trivial amount indicates a protest bid, that is, we assume the respondent is not willing to reveal their valuation of the imagery, in part to stave off potential price increases in Landsat imagery. It is customary to remove protest respondents from the statistical analysis (Mitchell and Carson, 1988). For this analysis, we removed protest respondents if they responded "No"/"No" and "No" to the $\$ 1$ amount. These respondents appear, and are treated, as if they are simply disagreeing with the spirit of the exercise. Therefore, it is not likely assessing their responses will provide accurate economic information.

\section{Annual Value of Landsat}

\section{Annual Landsat Downloads since 2011}

The annual value of Landsat depends on two factors: (a) the value per scene and (b) the number of scenes downloaded. So far, this report has focused on estimating the value per scene to the user. Figure 3 shows the time series of the trend in number of scenes downloaded since the last Landsat users survey in 2012. This 2012 survey asked respondents about the number of scenes downloaded in 2011, so the time series starts there. Since 2013, there has been an upward trend in scenes downloaded among U.S. users.

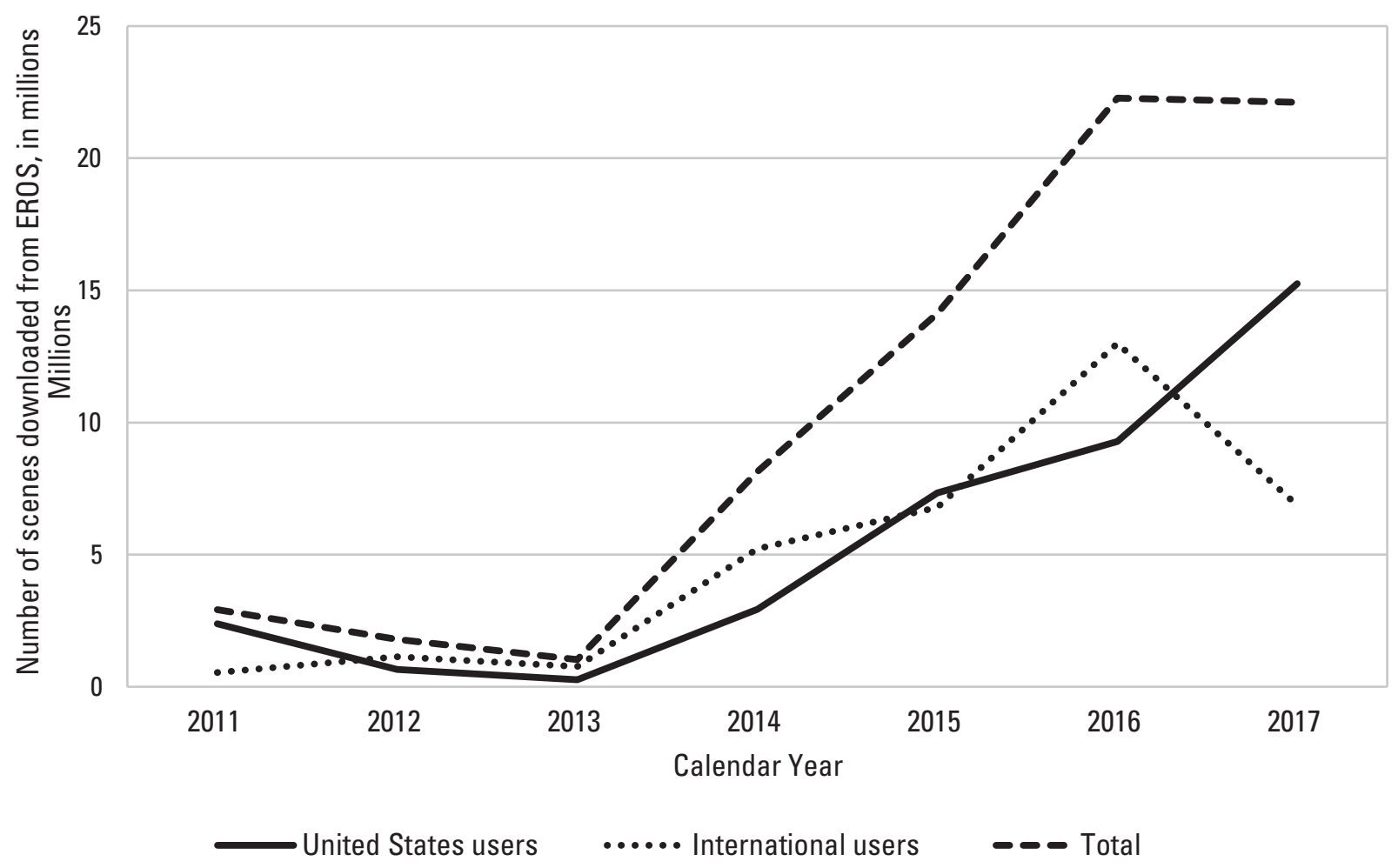

Figure 3. Use of Landsat imagery over time based on direct scenes downloaded from the Earth Resources Observation and Science (EROS) Center. (Sentinel-2A was launched on June 23, 2015, and Sentinel-2B followed on March 7, 2017.)

The number of downloaded scenes understates the total use of Landsat imagery. Anecdotal observations suggest that Landsat users are gravitating toward commercial cloud vendors to download and (or) process Landsat in the cloud. Because user interaction with Landsat data in commercial clouds cannot be captured through Earth Explorer (the U.S. Geological Survey portal for Landsat data access), data valuation methods based upon Earth Explorer user statistics will likely underestimate value. 
As this trend is expected to continue, alternative methods for assessing Landsat value will need to be considered. Specifically, future valuation efforts need to consider user interaction beyond the traditional data download model (Peter Doucette, personal communication, March 2019).

\section{Annual Total Valuation of Landsat Imagery to Direct Users}

Table 4 shows the total annual valuation of Landsat imagery to the direct/initial users of Landsat imagery who download the images from EROS. Table 4 reveals that, despite the reduced value per scene of Landsat imagery in 2017 (the number of downloaded scenes based on EROS registered users in calendar year 2017), the total value of Landsat imagery has increased. Specifically, we estimate that Landsat imagery provided domestic and international users $\$ 3.452$ billion in benefits in 2017 . This value ( $\$ 3.452$ billion) does not incorporate the number of scenes downloaded (from EROS) by cloud vendors. If you incorporate the number of scenes downloaded (from EROS) by cloud vendors, Landsat imagery provided domestic and international users $\$ 4.184$ billion in benefits in 2017 compared to \$2.192 billion in 2011 . We did not receive a large number of WTP responses from cloud vendor respondents. However, these few cloud vendor observations are included in our statistical analysis and hence our overall WTP estimates. Nonetheless, to provide a conservative estimate of value, the upper panel of table 4 provides an estimate of total annual value of Landsat without including the large volume of cloud vendor downloads. Therefore, a conservative estimate of the total value of Landsat imagery is $\$ 3.452$ billion (2017). The middle panel of table 4 includes the cloud vendors downloads and uses the overall sample value to arrive at an estimate of $\$ 4.184$ billion (2017).

Table 4. Annual aggregate economic benefits to Landsat users registered with the U.S. Geological Survey from Landsat imagery distributed by the Earth Resources Observation and Science (EROS) Center in 2011 and 2017.

\begin{tabular}{|c|c|c|c|c|}
\hline Year/Landsat user group & $\begin{array}{l}\text { Number of scenes } \\
\text { obtained from EROS }\end{array}$ & $\begin{array}{c}\text { Average economic } \\
\text { benefit per scene }\end{array}$ & $\begin{array}{l}\text { Annual economic } \\
\text { benefit (\$millions) }\end{array}$ & $\begin{array}{l}\text { Lower bound } \\
\text { (\$millions) }\end{array}$ \\
\hline \multicolumn{5}{|c|}{$\begin{array}{l}2017 \text { (Downloads from EROS excluding } \\
\text { downloads from cloud vendors) }\end{array}$} \\
\hline U.S. users & $11,250,000$ & $\$ 183$ & $\$ 2,059$ & $\$ 833$ \\
\hline International users & $6,862,632$ & $\$ 203$ & $\$ 1,393$ & $\$ 556$ \\
\hline U.S. users & $15,252,378$ & $\$ 183$ & $\$ 2,791$ & $\$ 1,129$ \\
\hline International users & $6,862,632$ & $\$ 203$ & $\$ 1,393$ & $\$ 556$ \\
\hline Total & $22,115,010$ & & $\$ 4,184$ & $\$ 1,685$ \\
\hline Total & $2,918,826$ & & $\$ 2,192$ & $\$ 1,998$ \\
\hline
\end{tabular}

\section{Conclusion}

Valuing goods that are not purchased through markets is a difficult exercise and process, but often a necessary one if information on the economic benefits of these goods is needed. Contingent valuation is one accepted approach for estimating economic benefits when there are no explicit markets for a good. The approach used in this report is consistent with procedures commonly used to conduct an original contingent valuation study. Although the survey response rate is comparable to other internet surveys, it is too low to have full confidence that the sample represents the population of primary Landsat users. This is compounded by additional factors such as user interaction beyond the traditional data download model including access to Landsat data through Amazon Web Services, the Environmental Systems Research Institute, Google Earth Engine, and other sources. 
This report applies the contingent valuation method to provide aggregated estimates of economic benefits to U.S. and international direct/initial users of Landsat images. Users that download a small number of scenes and have used Landsat imagery for many years place the highest value on the imagery. Private business users and Federal government users also place high value on the imagery relative to some other users, primarily academic users, State and local governments, and nonprofit organizations. Within the extensive group of Landsat imagery users, there is a small segment who have a very high value for the Landsat imagery. However, there is a substantial proportion that value Landsat imagery rather low compared to the next best substitute (Sentinel-2) or imagery obtained from other sources. If users were charged the approximate mean valuation of $\$ 183$ per scene, approximately 83 percent of Landsat users would not use Landsat, leaving just 17 percent of the current users. The confidence interval on this 17 percent is between 6.5 percent and 38 percent of users remaining at a charge of $\$ 183$ a scene. These remaining users would be only the long-time and low-number-of-scene users.

It is cautioned that, like all averages, this average of $\$ 183$ per scene is not a fixed, unchanging value, as it varies for different types of users. Specifically, all users do not receive $\$ 183$ per scene of value from Landsat imagery. This value is the average across users; although some users attach a high value to imagery, most users attach a relatively low value. The value also changes across time periods, as can be seen comparing the 2012 values to the value estimated in 2018 . This is not unique to the value of Landsat imagery, as the value of all goods changes over time (for example, gasoline, houses). One of the factors driving this change for Landsat imagery is the availability of substitute sources of satellite imagery.

The annual benefit in 2011 to U.S. users was estimated at approximately $\$ 1.8$ billion and in 2017 is estimated at approximately $\$ 2.1$ billion. Landsat imagery provided domestic and international users an estimated $\$ 3.452$ billion in benefits in 2017 compared to $\$ 2.192$ billion in 2011. However, the value per scene was substantially higher in 2011 when compared to 2017. Much of the societal value of Landsat stems from the free and open data policy that allows users to access as much imagery as is necessary for their analysis at no cost. Charging even small fees would result in a loss of users and, most likely, a steep decline in the amount of imagery downloaded. It is reasonable that more than 50 percent of users will decline to pay. The consequences of charging for Landsat imagery would be felt by downstream users as well, through increased prices for value-added products as well as more intangible effects, such as reduced monitoring of environmental hazards.

\section{Acknowledgments}

This study was funded by the U.S. Geological Survey's National Land Imaging Program. We would like to thank the numerous people who reviewed all of the surveys and provided constructive feedback.

\section{References}

Arrow, K., Solow, R., Portney, P.R., Leamer, E.E., Radner, R., and Schuman, H., 1993, Report of the NOAA panel on contingent valuation: Washington, D.C., U.S. Department of Commerce, National Oceanic and Atmospheric Administration, 66 p.

Brent, R., 1996, Applied benefit cost analysis: Cheltenham, United Kingdom, Edward Elgar, 445 p.

Campos, P., Caparrós, A., and Oviedo, J.L., 2007, Comparing payment-vehicle effects in contingent valuation studies for recreational use in two protected Spanish forests: Journal of Leisure Research, v. 39, no. 1, p. 60-85.

Champ, P.A., Boyle, K.J., and Brown, T.C., 2017, A primer for nonmarket valuation, second edition: Dordrecht, The Netherlands, Springer, $566 \mathrm{p}$.

Dillman, D.A., 2017, The promise and challenge of pushing respondents to the web in mixed-mode surveys: Survey Methodology, v. 43, no. 1, p. 3-30. [Also available at http://www.statcan.gc.ca/pub/12-001-x/2017001/article/14836-eng.pdf.]

Dillman, D.A., Smyth, J.D., and Christian, L.M., 2014, Internet, phone, mail, and mixed-mode surveys-The tailored design method (4th ed.): Hoboken, N.J., John Wiley Co., 528 p.

Hanemann, M., Loomis, J., and Kanninen, B., 1991, Statistical efficiency of double-bounded dichotomous choice contingent valuation: American Journal of Agricultural Economics, v. 73, no. 4, p. 1255-1263.

Leslie, C.R., Serbina, L.O., and Miller, H.M., 2017, Landsat and agriculture - Case studies on the uses and benefits of Landsat imagery in agricultural monitoring and production: U.S. Geological Survey Open-File Report 2017-1034, 27 p. [Also available at https://doi.org/10.3133/ofr20171034.] 
Loomis, J., Koontz, S., Miller, H., and Richardson, L., 2015, Valuing geospatial information-Using the contingent valuation method to estimate the economic benefits of Landsat satellite imagery: Photogrammetric Engineering \& Remote Sensing: v. 81 , no. 8, p. 647-656.

Loomis, J., Pierce, C., and Manfredo, M., 2000, Using the demand for hunting licenses to evaluate contingent valuation estimates of willingness to pay: Applied Economics Letters, v. 7, p. 435-438.

Miller, H.M., Richardson, L., Koontz, S.R., Loomis, J., and Koontz, L., 2013, Users, uses, and value of Landsat satellite imagery-Results from the 2012 survey of users: U.S. Geological Survey Open-File Report 2013-1269, 51 p. [Also available at https://doi.org/10.3133/ofr20131269.]

Mitchell. R.C., and Carson, R.T., 1989, Using surveys to value public goods_-The contingent valuation method: Washington, D.C., Resources for the Future, 484 p.

National Academies of Sciences, Engineering, and Medicine, 2018, Thriving on our changing planet —A decadal strategy for Earth observation from space: Washington, D.C:, The National Academies Press, 694 p. [Also available at https://doi.org/10.17226/24938.]

Office of Management and Budget, 1992, Guidelines and discount rates for benefit-cost analysis of Federal programs: Washington, D.C., Executive Office of the President, Office of Management and Budget Circular A-94, Revised Transmittal Memo \#64, 22 p. [Also available at http://www.whitehouse.gov/omb/circulars_a094.]

Office of Science and Technology Policy, 2014, National Plan for Civil Earth Observations: Washington, D.C., Office of Science and Technology Policy, 62 p.

Petchenik, J., and Watermolen, D.J., 2011, A cautionary note on using the Internet to survey recent hunter education graduates: Human Dimensions of Wildlife, v. 16, no. 3, p. 216-218.

Popkin, G., 2018, US government considers charging for popular Earth-observing data: Nature, v. 556, p. 417-418.

Serbina, L., and Miller, H.M., 2014, Landsat and water-Case studies of the uses and benefits of Landsat imagery in water resources: U.S. Geological Survey Open-File Report 2014-1108, 61 p. [Also available at https://doi.org/10.3133/ ofr20141108.]

Stokey, E., and Zechauser, R., 1978, A primer for policy analysis: New York, W.W. Norton and Company, 368 p.

Tourangeau, R., and Plewes, T.J., eds., 2013, Nonresponse in social science surveys-A research agenda: Washington, D.C.: The National Academies Press., 152 p.

Zhu, Z., Wulder, M.A., Roy, D.P., Woodcock, C.E., Hansen, M.C., Radeloff, V.C., Healey, S.P., Schaaf, C., Hostert, P., Strobl, P., Pekel, J.-F., Lymburner, L., Pahlevan, N., and Scambos, T.A., 2019, Benefits of the free and open Landsat data policy: Remote Sensing of Environment, v. 224, p. 382-385.

Publishing support provided by the Science Publishing Network,

Denver Publishing Service Center

For more information concerning the research in this report, contact the

Center Director, USGS Fort Collins Science Center

2150 Centre Ave., Bldg. C

Fort Collins, CO 80526-8118

(970) 226-9100

Or visit the Fort Collins Science Center web site at:

https://www.usgs.gov/centers/fort 


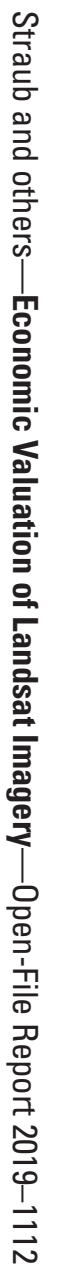

